\title{
AN ASSESSMENT OF STATIC RECRYSTALLIZATION IN L-605 COBALT-BASED SUPERALLOY
}

\author{
Padina Ajami Ghaleh Rashidi ${ }^{1 *}$, Hossein Arabi ${ }^{2}$, Seyed Mehdi Abbasi $i^{3}$ \\ ${ }^{1}$ School of Metallurgy and Materials Engineering, Iran University of Science \\ and Technology (IUST), Tehran, Iran \\ ${ }^{2}$ Center of Excellence for High Strength Alloys Technology (CEHSAT), School \\ of Metallurgy and Materials Engineering, Iran University of Science and \\ Technology (IUST), Tehran, Iran \\ ${ }^{3}$ Metallic Materials Research Center (MMRC-MA), Tehran, Iran
}

Received 22.09.2016

Accepted 17.11.2016

\begin{abstract}
In this research, the effect of cold rolling, annealing time and temperature on microstructure and hardness were studied in L-605 superalloy. A cast bar of L-605 alloy was hot rolled at $1200^{\circ} \mathrm{C}$. As the following, it was solutionized at $1230{ }^{\circ} \mathrm{C}$ for 1 hour and finally was cold rolled by different amounts (i.e. 5-35 percent thickness reduction). The cold-rolled samples were heat treated for different times (i.e. 2-120 min.) at temperature range of $1068-1230{ }^{\circ} \mathrm{C}$ in order to study their recrystallization behavior. The results of microstructural analysis indicated that static recrystallization is responsible for microstructural refinement and coarsening, so that an increase in the amounts of cold rolling resulted in a fully recrystallized microstructure at lower temperature. This analysis also indicated that annealing temperature is more effective than annealing time in grain growth. Microstructural evaluation as well as showed that carbides such as $\mathrm{M}_{7} \mathrm{C}_{3}$ and $\mathrm{M}_{23} \mathrm{C}_{6}$ which have been reported in some literature were not observed during rolling or annealing in this research. It is perhaps due to usage of high annealing temperatures or possibly due to their very low contents which was not possible for us to evaluate their formation with conventional methods. Hardness results revealed that higher annealing temperature lead to lower hardness values as expected. Keywords: recrystallization, annealing, cold rolling, grain size, L-605 superalloy
\end{abstract}

\footnotetext{
* Corresponding author: Padina Ajami Ghaleh Rashidi,ajami@alumni.iust.ac.ir
} 


\section{Introduction}

HAYNES 25 superalloy (also was known as L-605) is a cobalt-based superalloy with chemical composition Co-10Ni-20Cr-15W. This alloy can be used in applications that need high-temperature strength, good oxidation resistance and very good resistance to sulfide at service. It is weldable and can be formed by cold and hot working. Its strength can highly be improved by cold working due to dislocations slip and twinning and also due to stress induced martensite transformation (SIMT) during cold deformation mechanisms $[1,2]$.

Cold working is one of the most important processes in production of this type of alloys. During cold working, the alloy is deformed at room temperature to obtain a desired shape with exact dimensions. Recovery and Recrystallization processes do not occur during cold working, and therefore material hardness increases [3]. If a coldworked material is annealed, deformed grains will replace by a new fine and free strained grains. In fact, stored energy of cold working provides driving force for recrystallization [4].

During annealing, energy releases in three identifiable stages: recovery, recrystallization, and grain growth [4]. During recovery, there may be a very slight increase in hardening which is associated with re-arrangement of dislocations into a more stable configuration. In recrystallization, deformed grains replace by a new set of grains that nucleate and grow until the original grains have been entirely consumed. As a result, cold rolling followed by heat treatment results in recovery and static recrystallization in which new strain-free grains nucleate and grow inside the old distorted grains and at the grain boundaries. Thus, occurrences of these phenomena provide changes in microstructure and mechanical properties.

Improvement of strength and ductility in L-605 alloy depend on combination of different strengthening mechanisms [5]. It is said [2] that the grain size modification is the only known mechanism for simultaneous increase of strength and ductility. Therefore, it seems that investigate the effect of heat treatment on the cold-worked alloy in order to evaluate its static recrystallization and microstructure is very important. Limited studies have been reported for the effect of annealing on microstructure of L605 alloy. Therefore, one of the aims of this research is to examine the effect of various heat treatment cycles on the microstructure of cold-rolled L-605 alloy.

Also, it should be noted that L-605 alloy is primarily strengthened by carbides precipitation [5]. These precipitates form at low temperatures (usually below $1000^{\circ} \mathrm{C}$ ) and dissolve at high temperatures. Therefore, in this research a temperature range of $1068-1230^{\circ} \mathrm{C}$ was selected for annealing in order to prevent the formation of these carbides.

\section{Materials and Methods}

Hot-rolled (at $1200{ }^{\circ} \mathrm{C}$ ) L-605 alloy with chemical composition 80Co-20Ni-4W$0.1 \mathrm{C}$ was used in the present work. The hot-rolled bar was solutionized at $1230^{\circ} \mathrm{C}$ for 1 hour. The solution annealing process caused an increase in cold workability during cold rolling. Solution treated samples were cold rolled (CR) up to 5, 10, 20, 30 and $35 \%$ thickness reduction. Then, each of the cold-rolled samples was annealed at 1068, 1120, 1175 and $1230{ }^{\circ} \mathrm{C}$ from 2 to $120 \mathrm{~min}$. As the following, they were cooled in the open air. 
Microstructures of the samples in each state of treatment were evaluated by optical microscopy (OM), scanning electron microscopy (SEM) and XRD. Homogenous single phase austenite was observed in all cases. Worth mentioning, due to a large amount of data and a large number of micrographs obtained for quantitative measurements only a few selected micrographs are presented in this paper to avoid high number of paper pages.

For microstructural studies samples were grind up to No.1500 silica paper and then polished by 1 micron alumina to finish before etching them in a solution of $30 \mathrm{ml}$ $\mathrm{HCl}, 7 \mathrm{ml} \mathrm{H}_{2} \mathrm{O}$, and $3 \mathrm{ml} \mathrm{H}_{2} \mathrm{O}_{2}$. Average grain size was measured by using Clemex software. A Bruker AXS D8ADVANCE X-ray diffractometer was used for phase identification in selected samples. $\mathrm{X}$-ray source was $\mathrm{Cu}-\mathrm{K}_{\alpha}$ radiation $(\mathrm{X}$-ray tube with $45 \mathrm{kV}$ and $30 \mathrm{~mA}$ ). Analysis was carried out in the range of $0-2 \theta$.

To see the effect of microstructural changes on hardness, the hardness of the samples was measured by Vickers method using a load of $30 \mathrm{kgf}$. Universal Hardness Tester Koopa UV1 model was used. The average of the hardness quoted in this research is the result of at least 3 times measurement for each sample. A summary of mechanical and annealing conditions that were applied in this research was presented in Table 1.

Table 1: Summary of Mechanical and Annealing Conditions Applied in This Research.

\begin{tabular}{|c|c|c|c|}
\hline \multirow{2}{*}{$\begin{array}{c}\text { Condition of the } \\
\text { Initial Alloy } \\
\text { L-605 }\end{array}$} & $\begin{array}{c}\text { Amount of Cold Rolling } \\
\text { (thickness reduction) } \\
(\%)\end{array}$ & $\begin{array}{c}\text { Annealing Condition } \\
\text { Range of Ann. } \\
\text { Temperature } \\
(\mathbf{\%} \mathbf{C})\end{array}$ & $\begin{array}{c}\text { Range of Ann. } \\
\text { Time for each } \\
\text { Temperature, } \\
\text { (min) }\end{array}$ \\
\hline \multirow{3}{*}{$\begin{array}{c}\text { Hot Rolling at } 1200^{\circ} \mathrm{C} \\
+ \text { Solution at } 1230^{\circ} \mathrm{C} \\
\text { for } 1 \mathrm{~h}\end{array}$} & 5 & $1068-1230$ & $2-120$ \\
\cline { 2 - 4 } & 10 & $1068-1230$ & $2-120$ \\
\cline { 2 - 4 } & 20 & $1068-1230$ & $2-120$ \\
\cline { 2 - 4 } & 30 & $1068-1230$ & $2-120$ \\
\hline
\end{tabular}

\section{Results and Discussion}

\section{Effect of Thickness Reduction on Microstructure}

The average grain size of the samples after 5, 10, 20, 30 and $35 \%$ reduction changed from $154 \mu \mathrm{m}$ (i.e. for the solution sample) to $157,162,165,176$ and $181 \mu \mathrm{m}$ respectively. Micrographs that were presented in Fig. 1 clearly show that grains were elongated in the direction of rolling. Slip lines can be observed in the closed-packed planes (i.e. $\{111\}$ ). With increasing deformation from 5 to $35 \%$, slip bands can be observed in more planes. This is an indication of grains rotation, alignment of more slip systems in following direction and operation of more slip systems.

Slip lines are due to directional accumulation of dislocations in highly packed slip planes that can be observed after etching. At higher strain, that is 20,30 and 35\%, more slip systems were active and the increase in grains size along rolling direction and the decrease in perpendicular direction is very evident.

The change in grains dimensions during deformation indicates the material flow in rolling direction [6,7]. It should be noted that since crystal directions are randomly distributed, dislocations slip lines cannot be observed in all grains within a cross section 
unless the closed-packed planes align themselves in a similar direction during deformation (i.e. a particular texture develops). Therefore, for FCC materials which dislocations can easily glide in $\langle 110\rangle$ closed-packed directions in $\{111\}$ close-packed planes when subjected to deformation the flow of material is in such a way that the $\{111\}$ planes align themselves in rolling direction. So, by applying more deformation more alignment occurred which resulted to observation of more slip lines.

Also, various presented micrographs in Fig. 1 show that the cold-rolled samples consist of a single phase.
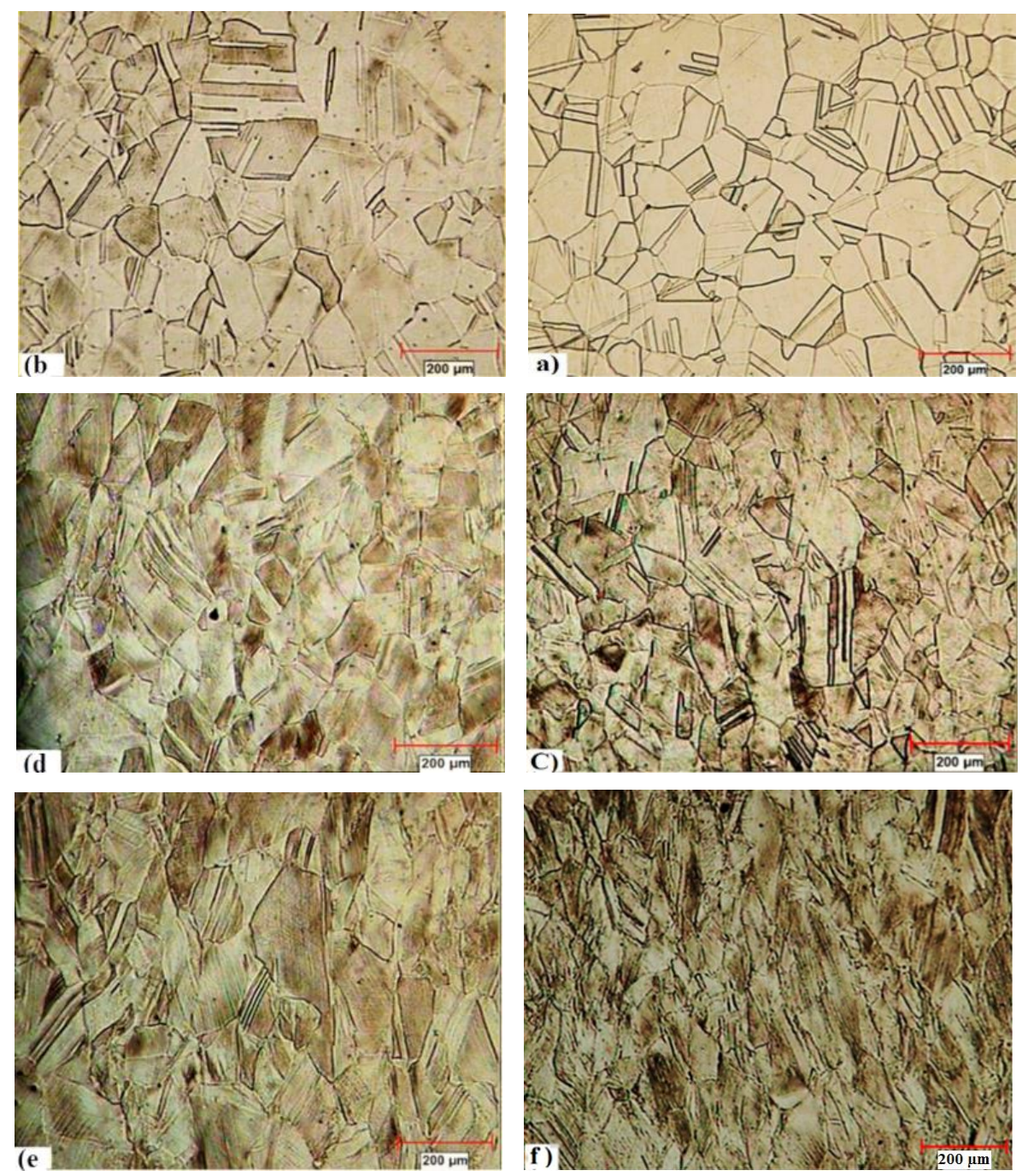


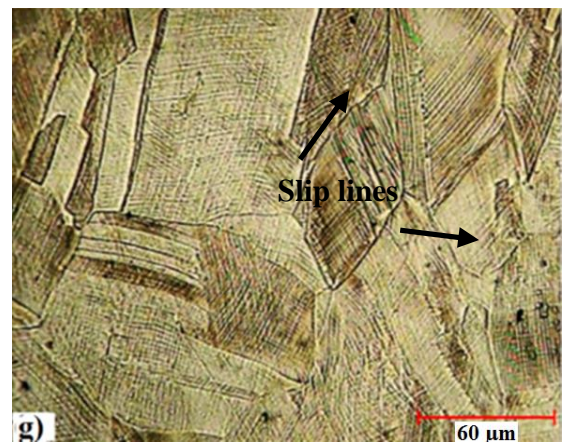

Fig. 1. OM Images of As-rolled Materials (a) $0 \%$ Cold Rolled (CR), (b) 5\% CR, (c) $10 \% \mathrm{CR}$, (d) 20\% CR, (e) 30\% CR, (f) and (g) $35 \%$ CR at 2 Magnification, Showing Slip Lines All Over the Closed-packed Planes.

Effect of Annealing Heat Treatment on The Microstructure of Cold-rolled Alloy

Fig. 2 shows typical SEM images of 10 and $30 \%$ cold-rolled samples after annealing at $1230^{\circ} \mathrm{C}$ for $30 \mathrm{~min}$. These images show while the slip lines disappeared and some thermal twins emerged within the microstructure of the alloy after annealing, no detectable precipitate has been formed. The obtained results for other annealing temperatures and times were similar.
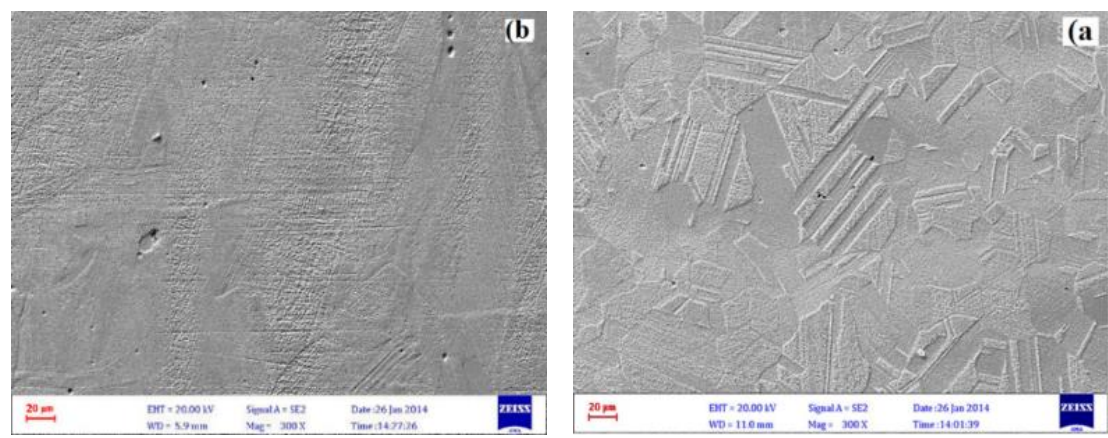

Fig. 2. SEM Micrographs of (a) $10 \%$ CR (b) $30 \%$ CR, After Annealing at $1230{ }^{\circ} \mathrm{C}$ for $30 \mathrm{~min}$.

In spite of no observation of any carbide within the microstructure before and after annealing, it has been reported [8] that carbides such as $\mathbf{M}_{23} \mathrm{C}_{6}$ and $\mathrm{M}_{6} \mathrm{C}$ are usually form in L-605 superalloy during annealing. Formation of hexagonal $\mathrm{M}_{7} \mathrm{C}_{3}$ carbide has occasionally been reported in this alloy [8]. Yukawa and Sato [9] also reported the formation of some intermetallic phases and carbides in L-605 superalloy. They summed up their results in a Time-Temperature-Precipitation (TTP) diagram. This diagram shows different types of precipitate which can be formed in L-605 superalloy.

Based on this diagram, it can be expected that $\mathrm{M}_{23} \mathrm{C}_{6}$ and $\mathrm{M}_{7} \mathrm{C}_{3}$ carbides start precipitating at $1068{ }^{\circ} \mathrm{C}$ after $40 \mathrm{~min}$. Also, after annealing at $1068{ }^{\circ} \mathrm{C}$ for 1 and 6 hours $\mathrm{M}_{6} \mathrm{C}$ and $\mathrm{Co}_{2} \mathrm{~W}$ phases are formed respectively. However, when this alloy was annealed at $1120{ }^{\circ} \mathrm{C} \mathrm{M} \mathrm{M}_{6} \mathrm{C}$ precipitated after 2.5 hours and $\mathrm{Co}_{2} \mathrm{~W}$ phase after 8 hours. Annealing at temperatures above $1200{ }^{\circ} \mathrm{C}$ resulted to formation of a single solid solution of austenite. 
SEM images of cold-rolled samples, Fig. 3, confirm the presence of single phase before and after annealing for the various times at $1068,1120,1175,1230{ }^{\circ} \mathrm{C}$ in this research. In fact, no secondary phase was detected by SEM or EDS in this study; although it was expected at lower annealing temperatures (i.e. Less than $1200^{\circ} \mathrm{C}$ ) some carbides be formed. The lack of observation of these carbides maybe is due to the lack of suitable high tech equipment as well as the possible low content of these phases in this study.

Fig. 3 shows typical images of $10 \%$ deformed samples after annealing at $1230^{\circ} \mathrm{C}$ for 10, 30 and $120 \mathrm{~min}$. EDX profiles and SEM images are good indications of the existence of an austenite phase matrix before and after annealing (Figs. 3 and 4). Only austenite matrix can be seen with etch pits in these samples. EDX results from the very small white points that observe in Fig. (3c) show that these are alumina particles that adhered to surface during polishing the samples with alumina solution. According to the initial amount of carbon in this alloy $(0.13 \mathrm{Wt} \%)$ and also the same reported amount in similar alloy by Favre [5], can say with this amount of carbon, formation of carbides is not possible especially in less than 1 hour annealing at $1230^{\circ} \mathrm{C}$. EDX analysis of matrix indicates that this alloy is single austenite phase. However, there is a possibility of carbide formation at temperatures lower than $1200{ }^{\circ} \mathrm{C}$ according to Yukawa and Sato [9], but as it was mentioned before arguably detection of these phases by utilizing the conventional methods is hard.
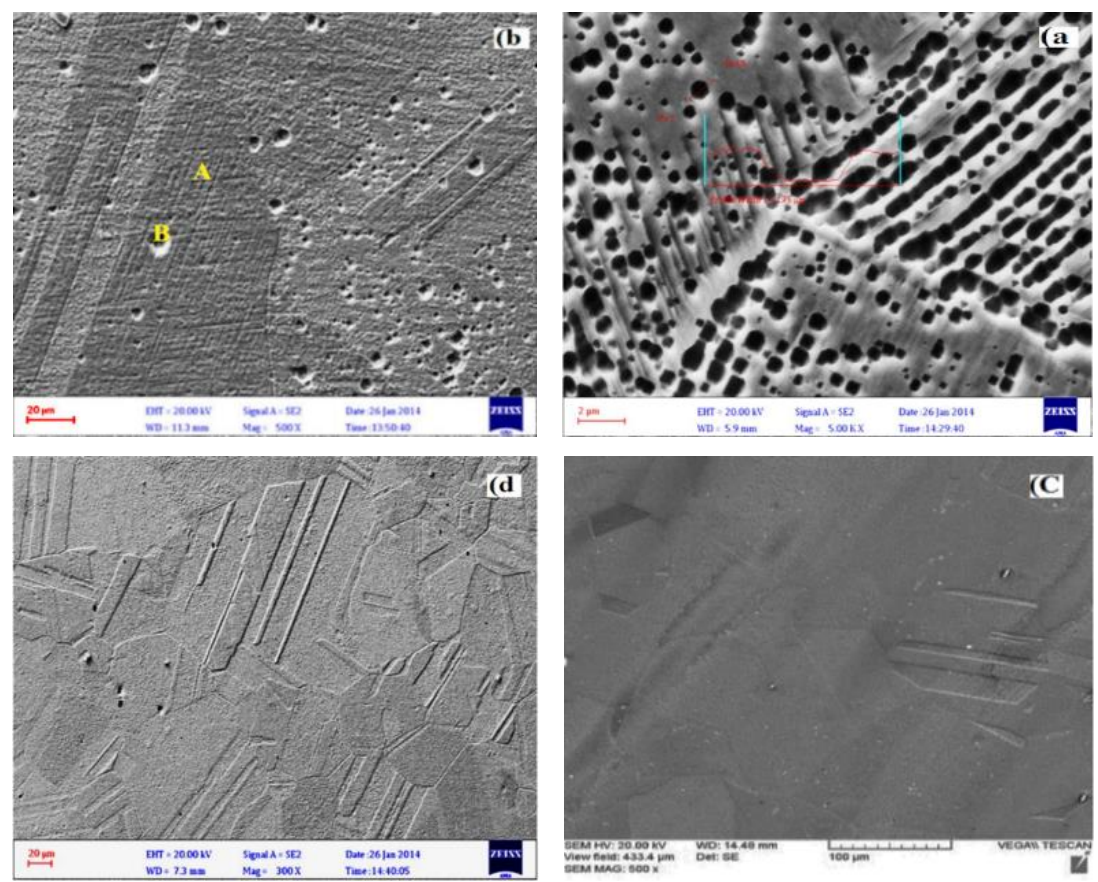

Fig. 3. SEM Micrographs of (a) 10\% Cold-rolled (CR), (b) 10\% CR and Annealed for $10 \mathrm{~min},(\mathrm{c}) 10 \% \mathrm{CR}$ and Annealed for $30 \mathrm{~min},(\mathrm{~d}) 10 \% \mathrm{CR}$ and Annealed for $120 \mathrm{~min}$, at $1230^{\circ} \mathrm{C}$. 


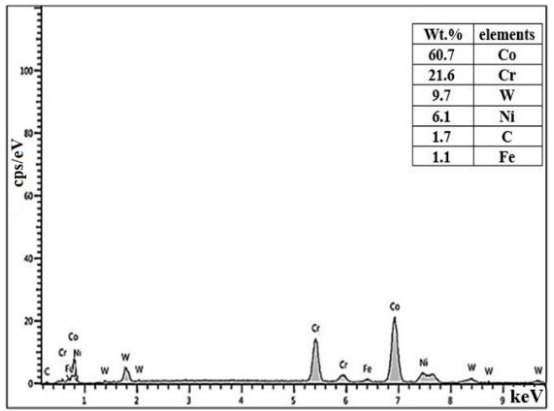

a)

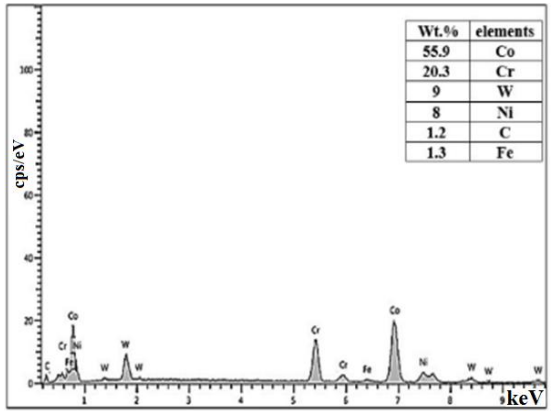

b)

Fig. 4. EDX Analysis, (a) EDX of Point A, (b) EDX of Point B shown in Fig. 3-b.

\section{Grain Growth}

Typical OM images of the cold-rolled samples that annealed at $1230^{\circ} \mathrm{C}$ for 120 min were presented in Fig.5 and variation of the grain size with annealing time was shown in Fig. 6. These figures show that the average grain size of the cold-rolled samples increases after annealing at $1230^{\circ} \mathrm{C}$ for different times with increasing amounts of deformation; for samples with the higher percentage of cold working (i.e. $20 \%, 30 \%$, $35 \%)$ this effect is much more aggravated.
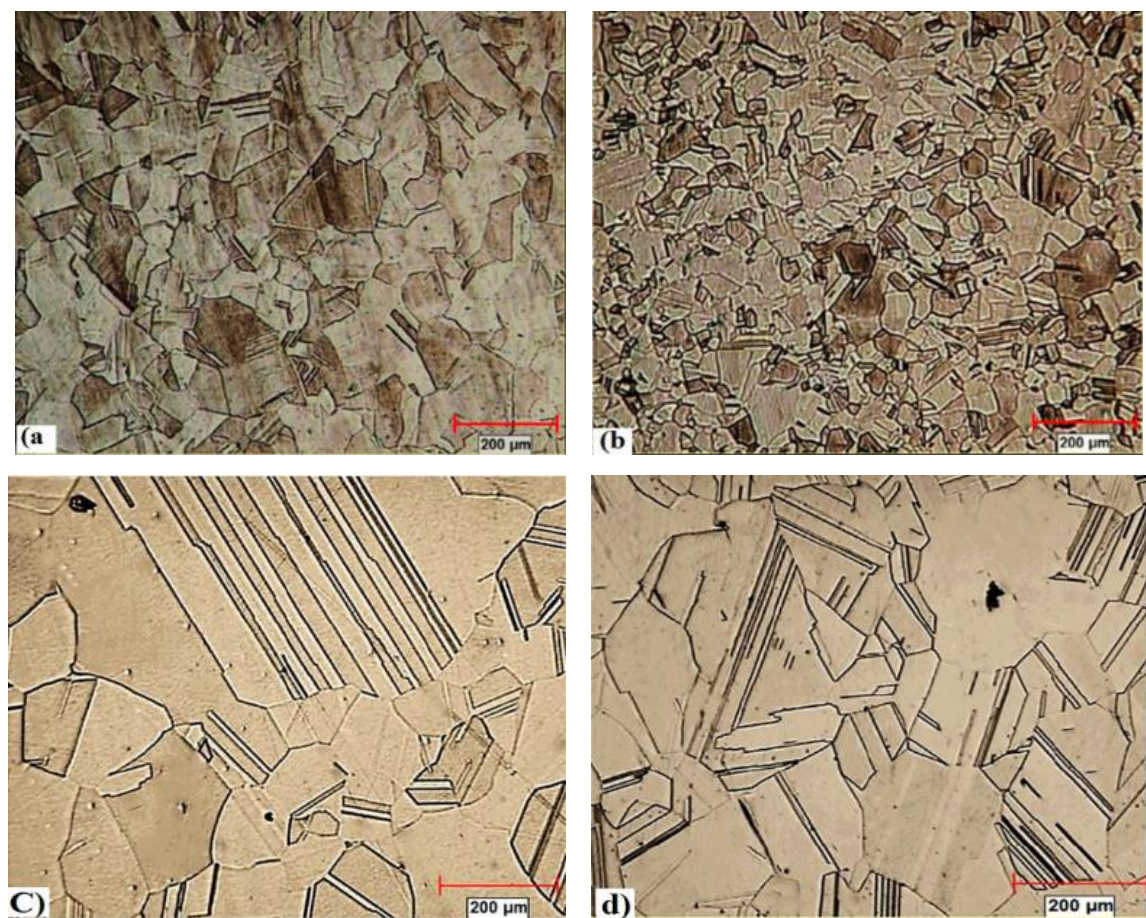


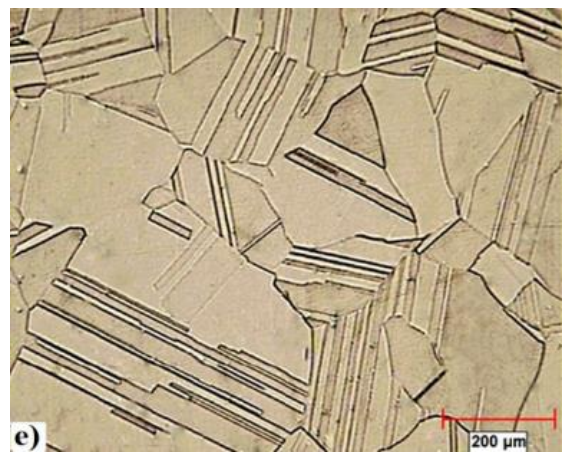

Fig.5. OM Images of the Samples Microstructure, (a) 5\% CR , (b) $10 \%$ CR, (c) $20 \%$ $C R$, (d) $30 \%$ CR, (e) $35 \%$ CR, After Annealing at $1230{ }^{\circ} \mathrm{C}$ for $120 \mathrm{~min}$.

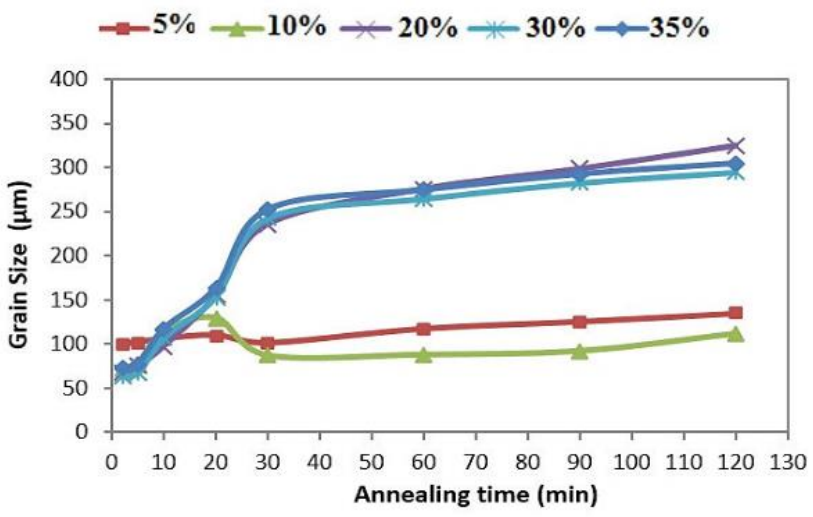

Fig. 6. The Effect of Various Amounts of the Thickness Reduction and Annealing Time on the Average Grain Size After Annealing at $1230^{\circ} \mathrm{C}$.

In 5 and $10 \%$ cold-rolled samples, increase in the average grain size after annealing for 20-30 $\mathrm{min}$ is due to growth of recrystallized and deformed grains since a tendency to achieve a balance between the grain boundaries surface energy and the stored energy inside grains, due to dislocation accumulation, constitutes driving force for grain growth [4]. Whereas, dislocations density within the grains is very high due to plastic deformation, according to the references [4], the contribution of surface energy to the grain migration usually can be neglected.

Several grain growth models for recrystallization have been developed by Sandstrom and Lagneborg [10]. These models assume the driving force is equal to the stored energy of the dislocation structure in an un-recrystallized material. Therefore, if dislocations density of the recrystallized grains is assumed to be null, in early stages of the recrystallization grains growth will be high due to difference in dislocations density between the deformed and un-deformed grains. However, in the next stage grains growth decreases because of a lower dislocations density. In addition, since the rate of dislocations motion is usually much more rapid than the rate of grain boundaries migration [11], hence the grains growth rate should be increased again with continuing the recrystallization process. 
A more detailed look at Fig. 6 reveals that the average grain size decreased slightly in some cases. This can be related to Zener pinning phenomenon [12].

According to the Zener mechanism, the fine carbides, which have not been recognizable with conventional methods in this study, impose a strong resistance to grain boundaries migration and eventually pin them. As soon as the moving grain boundary meets the carbide, the surface tension starts to pull boundary towards the carbide. From the moment when the boundary is trying to break away from the particle, the contact angle changes sign and the surface tension is now pulling the boundary back. This creates the pinning force that does not allow boundary to move on easily [12]. Therefore, the grains growth is limited over annealing in some circumstances and the average grain size reduces to some extent. It should be noted that in specimens with the high percentage of cold work due to existence of extremely fine carbides, the particles may no longer have been effective at pinning boundaries.

These trends also occurred in the samples that were annealed at $1175^{\circ} \mathrm{C}$. Variations of the average grain size versus annealing time for the samples that were annealed at $1175{ }^{\circ} \mathrm{C}$ was shown in Fig. 7. Furthermore, the average grain size of $20 \%$ cold-rolled samples and annealed for various times at $1175^{\circ} \mathrm{C}$ and $1230{ }^{\circ} \mathrm{C}$ have been presented in Table 2 .

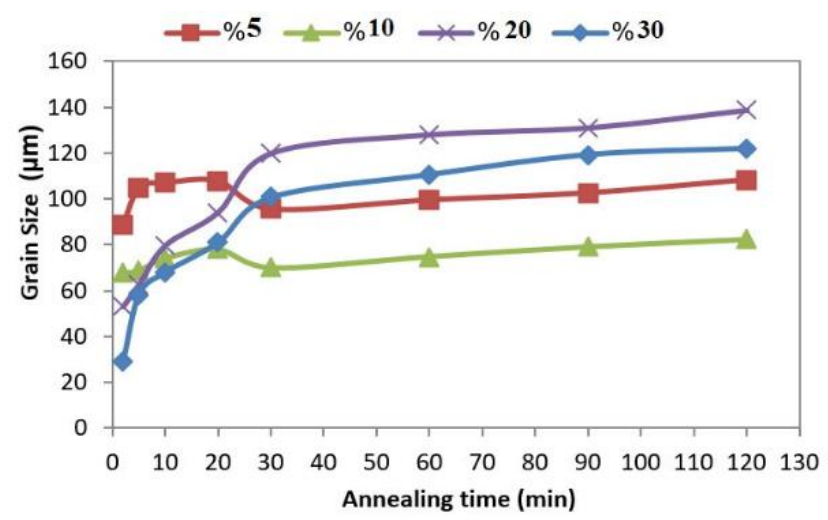

Fig. 7. Variations of the Average Grain Size Versus Annealing Time for the Cold-rolled samples of L-605 Alloy that Annealed at $1175^{\circ} \mathrm{C}$.

Table 2. Average Grain size for $20 \%$ Cold-rolled Samples that Annealed for Various Times at $1175^{\circ} \mathrm{C}$ and $1230^{\circ} \mathrm{C}$.

\begin{tabular}{|c|c|c|c|c|c|c|c|c|c|c|}
\hline & & \multicolumn{9}{|c|}{ Average grain size $(\mu \mathrm{m})$} \\
\hline \multicolumn{2}{|c|}{$\begin{array}{l}\text { Annealing time } \\
\text { (min) }\end{array}$} & $* \mathbf{0}$ & 2 & 5 & 10 & 20 & 30 & 60 & 90 & 120 \\
\hline Annealing & 1175 & 165 & $58 \pm 5$ & $63 \pm 6$ & $80 \pm 6$ & $94 \pm 6$ & $120 \pm 6$ & $128 \pm 10$ & $131 \pm 15$ & $139 \pm 15$ \\
\hline$\left({ }^{\circ} \mathrm{C}\right)$ & 1230 & 165 & $71.5 \pm 8$ & $75 \pm 8$ & $98 \pm 9$ & $155 \pm 9$ & $236 \pm 9$ & $276 \pm 10$ & $299 \pm 20$ & $325 \pm 20$ \\
\hline
\end{tabular}

*zero time $=$ cold rolled condition 
It should be noted that for the samples which were deformed about $20 \%$ the average grain size of the annealed samples increased by a great amount in comparison with the others.

The grain growth in samples that were annealed at $1230{ }^{\circ} \mathrm{C}$ for different times is remarkable. For instance, after $90 \mathrm{~min}$ annealing at $1230{ }^{\circ} \mathrm{C}$ the average grain size increased from 165 to $299 \mu \mathrm{m}$ that is a very high percentage of grain growth (i.e. $81 \%$ ). While, after annealing at the same temperature but less than $20 \mathrm{~min}$ (e.g. for $10 \mathrm{~min}$, see Table 2) the amount of growth is less than $40 \%$. Variation in the grain size particularly at higher annealing times is a good illustration of an abnormal grain growth during the annealing process.

The abnormal grain growth usually occurs in the vicinity of precipitates, so that it can be explained in terms of Zener pinning of grain boundaries. The random placement of the carbides results in abnormal grain growth. Moreover, there is another possibility that describes the abnormal boundary migration might have been due to secondary recrystallization.

It has reported $[13,14,16]$ that variation in the grains size is responsible for growing of some grains in secondary recrystallization particularly in single phase materials; it has also been reported [13] that deformed grains have higher potential for growth than other grains during the first step of recrystallization and are more suitable for secondary recrystallization. Therefore, the variation in grain size can be attributed to secondary recrystallization due to development of fine grains that stimulates prevention of the natural growth. These can be considered as the main factor for secondary recrystallization. Driving force for this abnormal growth is reduce in boundaries energy $[14,15]$. In fact, it can be said that the microstructure of a material may become unstable after the primary recrystallization and get a tendency to increase its grains size. Whereas the driving force for grains growth is lower than recrystallization, the rate of abnormal grain growth will be lower in comparison to normal growth [16]. Abnormal grain growth is severely time dependent phenomenon.

Another factor which can influence abnormal grain growth is existence of strong texture in the primary recrystallized grains [14]. It is said [14] that a stronger texture facilitates abnormal grain growth. It means that the stronger texture provides low angle boundaries, hence the mobility of these boundaries decreases and prevention of grains growth occurs much easier. As the following, grains growth interferes with stronger texture and accelerates the growth of some others with less strong texture. Therefore, secondary recrystallization occurs due to this unbalanced growth [16].

\section{Static Recrystallization}

Fig. 8 shows the microstructures of $35 \%$ cold-rolled alloy after annealing for 2 min at $1068{ }^{\circ} \mathrm{C}$ and $1175^{\circ} \mathrm{C}$. Annealing caused a reduction in average grain size from $125 \mu \mathrm{m}$, for $35 \% \mathrm{CR}$ sample, to 22 and $38 \mu \mathrm{m}$ for annealed samples at $1068{ }^{\circ} \mathrm{C}$ and $1175{ }^{\circ} \mathrm{C}$ respectively. This grain size reduction can be attributed to static recrystallization that involves nucleation of new grains within the deformed ones.

For longer annealing times in all temperatures further increase in the average grain size was observed. This was due to grain growth after recrystallization and an indication of completion of recrystallization process. It should be noted that static recrystallization starts and finishes in a fraction of a minute in $35 \%$ cold-rolled sample. 

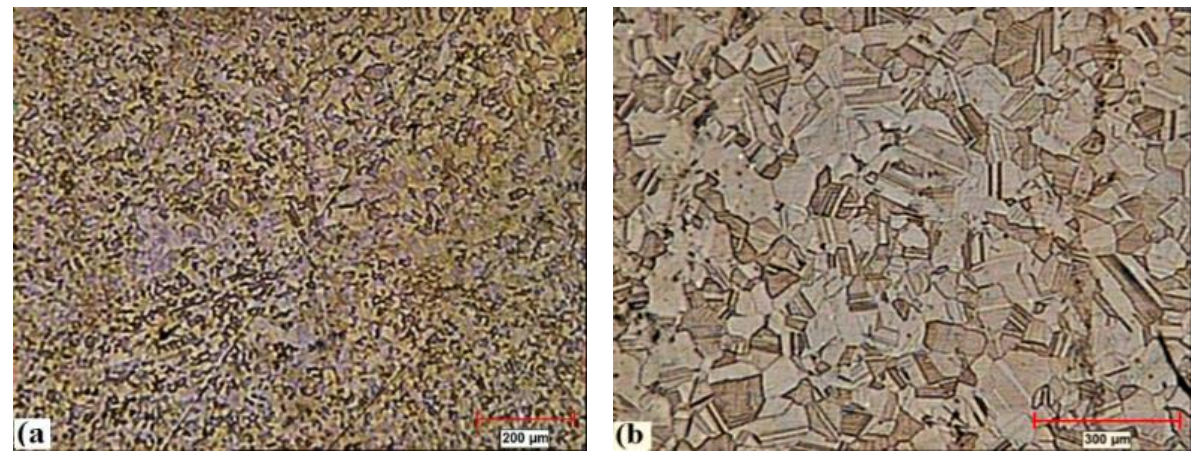

Fig. 8. OM Micrographs of $35 \%$ Cold-rolled Sample After Annealing at, (a) $1068{ }^{\circ} \mathrm{C}$ and (b) $1175^{\circ} \mathrm{C}$ for $2 \mathrm{~min}$.

Since recrystallization is a thermal activated process therefore, by increasing annealing temperature the diffusion rate of atoms goes up; hence recovery and recrystallization will be accelerated according to the reference [17]. This behavior indicates that recrystallization rate can be determined according to the Arrhenius or rate equation [18]:

$$
\frac{1}{t}=A \cdot \exp \left(-\frac{Q}{R T}\right)
$$

Where $\mathrm{t}$ is the processing time, $\mathrm{Q}$ activation energy of recrystallization, $\mathrm{R}$ universal gases constant and $\mathrm{T}$ is temperature in kelvin. According to Eq. (1), recrystallization rate will increase by increasing temperature.

Fig. 9 shows microstructure of 5, 20 and $30 \%$ cold-rolled samples after heat treatment at $1175{ }^{\circ} \mathrm{C}$ and $1230{ }^{\circ} \mathrm{C}$ for $10 \mathrm{~min}$. These micrographs show that by increasing the amounts of cold work from 5 to $30 \%$, the whole microstructure recrystallizes after annealing the samples at $1175^{\circ} \mathrm{C}$ and $1230{ }^{\circ} \mathrm{C}$ for $10 \mathrm{~min}$. However, about the samples were deformed $20 \%$ only the one that was annealed at $1230{ }^{\circ} \mathrm{C}$ became fully recrystallized after $10 \mathrm{~min}$. The other one which was annealed at $1175^{\circ} \mathrm{C}$ for 10 min partially recrystallized.

The 5\% CR samples either recrystallized partially after annealing for $10 \mathrm{~min}$ in both temperatures. This means that recrystallization of the cold-rolled samples and subsequent grain growth are very dependent on annealing temperature and time. So, in order to obtain a fully recrystallized microstructure for any certain amount of deformation without getting into grain growth should choose a right combination of annealing time and temperature.

Energy stored due to cold work increases with increasing strain. Therefore, nucleation and growth in more deformed samples occur at lower temperature and with a higher rate. On the other hand, new grains preferably nucleate in regions that have more orientation and deformation changes. According to the some literatures [19], high angle grain boundaries, slip bands and rotation of different crystals are preferred locations for nucleation that trigger increase in recrystallization rate. 

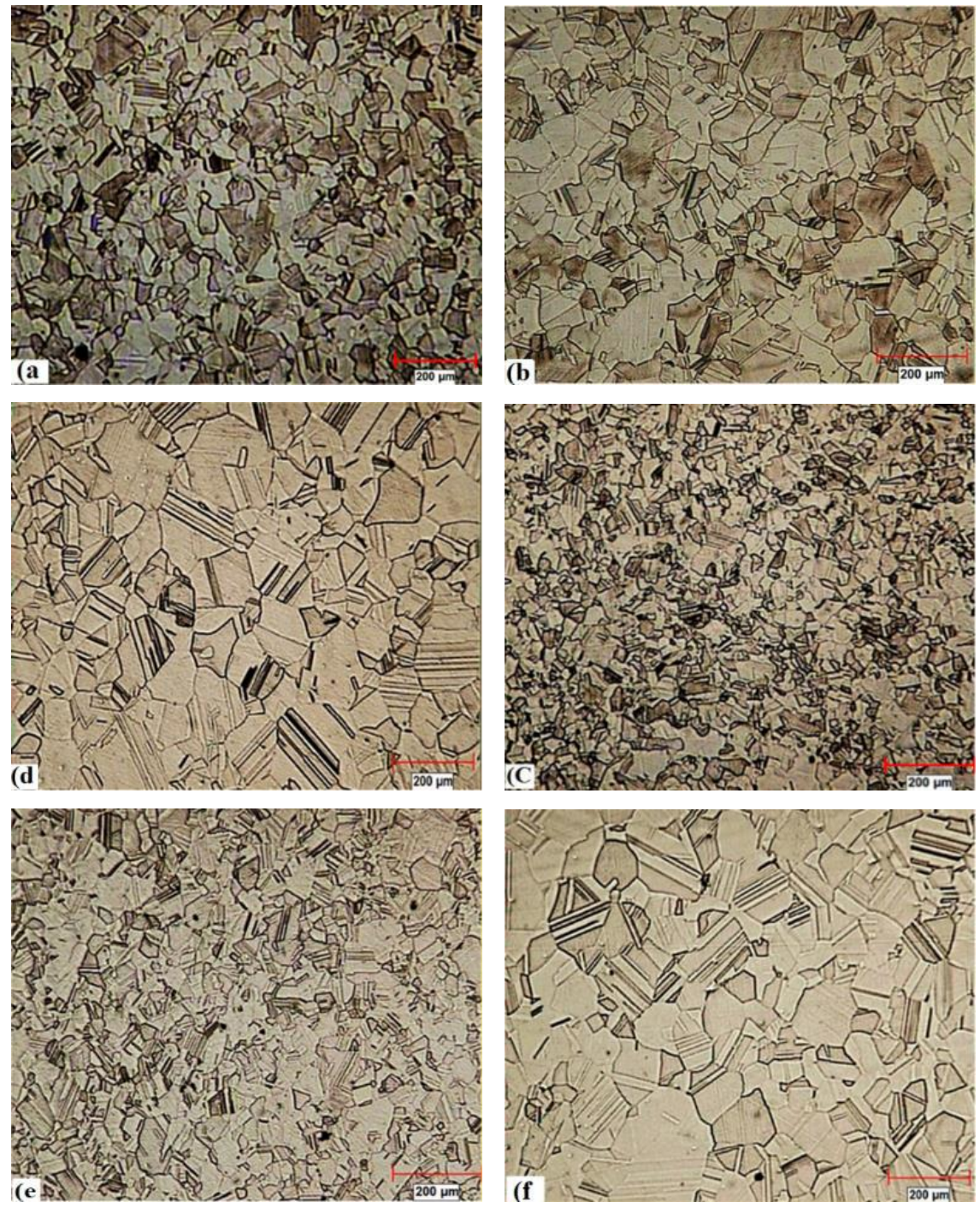

Fig.9. OM Images of the Cold-rolled and Annealed Samples at $1175^{\circ} \mathrm{C}$ and $1230^{\circ} \mathrm{C}$ for

$10 \mathrm{~min},\left(\right.$ a) $5 \% \mathrm{CR}+$ Ann.at $1175^{\circ} \mathrm{C},\left(\right.$ b) $5 \% \mathrm{CR}+$ Ann.at $1230^{\circ} \mathrm{C}$, (c) $20 \%$

$C R+$ Ann.at $1175^{\circ} \mathrm{C}$, (d) $20 \% \mathrm{CR}+$ Ann.at $1230^{\circ} \mathrm{C}$ (e) $30 \% \mathrm{CR}+$ Ann.at $1175^{\circ} \mathrm{C}$, (f) $30 \%$ CR+Ann.at $1230^{\circ} \mathrm{C}$.

\section{Hardness}

The mean hardness of the cold-rolled samples substantially increased in comparison with the relative amount of the solution sample which had an average hardness of 250 in Vickers scale. Some of the results of hardness's measurement were presented in Fig10. Zero times in this figure show the hardness of the CR samples before annealing. For instance, the sample that was cold rolled for 35\% (Fig.10e), its' hardness increased from $250 \mathrm{HV}_{30}$ to $545 \mathrm{HV}_{30}$, which increased by $119 \%$. After 
annealing, the hardness of the CR samples even for very short times (i.e.2 min) at $1175^{\circ} \mathrm{C}$ or $1230^{\circ} \mathrm{C}$ dropped roughly to near the hardness of the solution material $(250$ $\mathrm{HV}_{30}$ ). For example, when $35 \% \mathrm{CR}$ alloy was annealed for $2 \mathrm{~min}$ at $1068{ }^{\circ} \mathrm{C}$ its' hardness decreased by $39 \%$ and when were annealed at $1120^{\circ} \mathrm{C}, 1175^{\circ} \mathrm{C}$ and $1230{ }^{\circ} \mathrm{C}$ its' hardness decreased by $44 \%, 50 \%$ and $54 \%$ respectively. Further, increase in annealing times did not substantially affect the hardness of the alloy.

Increase in hardness during cold rolling can be attributed to increase in dislocations density which causes an increase in internal stress of the bulk of material [20]. Moreover, an induced stress by grain boundaries as well as internal defects can be attributed to formation of more new dislocations when more deformation is applied [4]. However, during annealing the softening of microstructure occurs; so, the cold-rolled material lowers its energy and becomes recrystallized.

Since stacking fault energy is low in L-605 alloy [21], most of the work hardening occurs at the beginning of the deformation process by rapid movement of dislocations in easy glide system. Due to large amount of work hardening and subsequently increase in stored energy in L-605 alloy [4], it seems that recrystallization is the dominant phenomenon in comparison with recovery. So, it can be said that by annealing at $1175^{\circ} \mathrm{C}$ and $1230{ }^{\circ} \mathrm{C}$ the average hardness goes down rapidly.
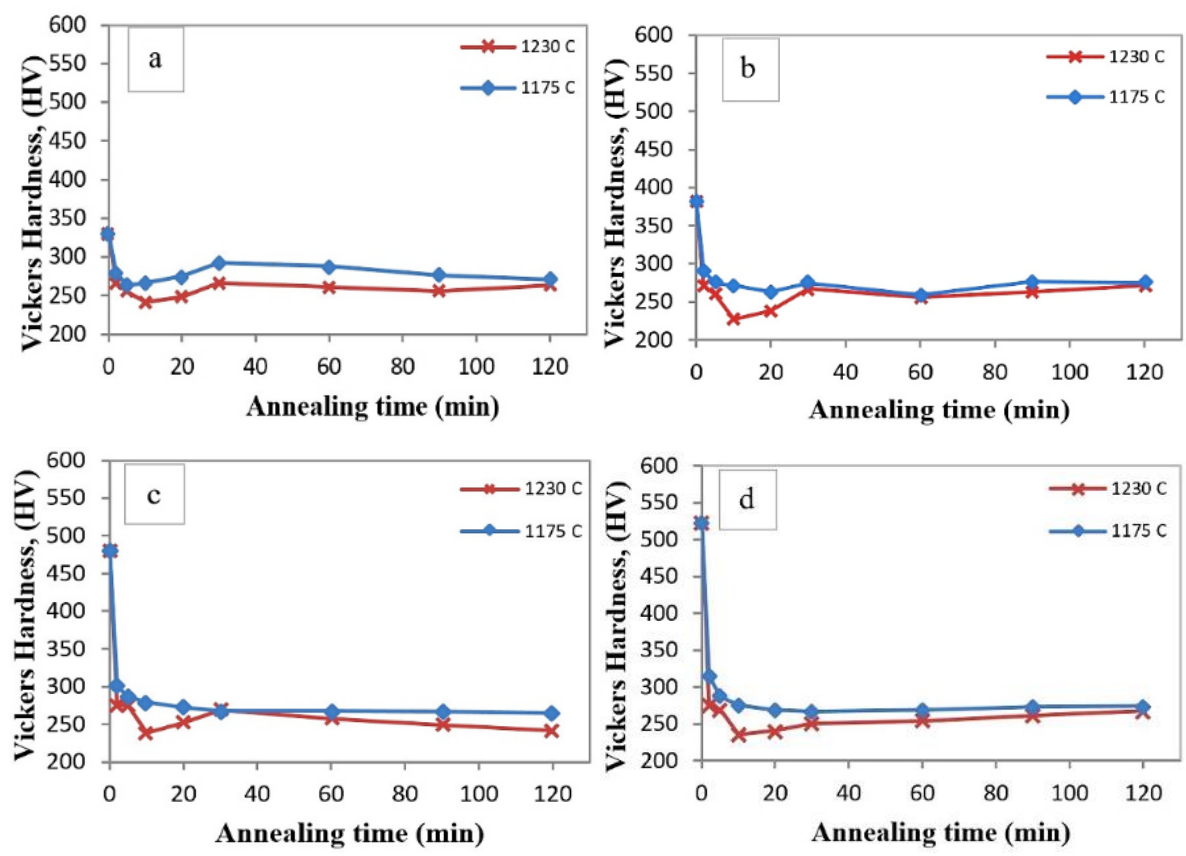


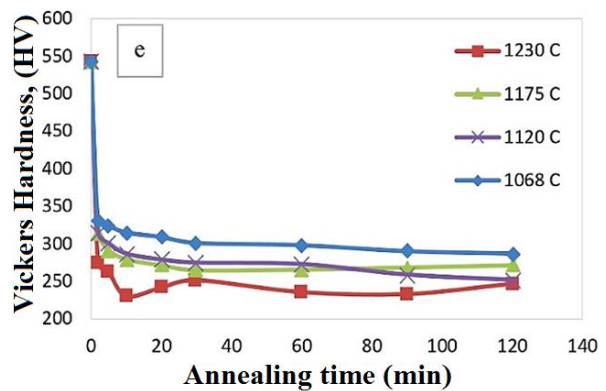

Fig. 10. Variations of the Hardness with Annealing Time and Temperature for Various Amounts of Cold rolling (a)5\%, (b)10\%, (c)20\%, (d) 30\% and (e)35\%.

As shown in Fig. 10, despite grain growth hardness increases gradually in $5,10,20,30$ and $35 \%$ cold-rolled samples after heating at $1230{ }^{\circ} \mathrm{C}$ for the range time of 10-120 min. According literatures [22], this can be because of SIMT occurrence.

Asgari and et al [23] have reported that grain size of a 35\% cold-worked and heat treated MP35N Ni-Co superalloy at $950{ }^{\circ} \mathrm{C}$ for 2 hours is comparable with those heat treated for more than 2 hours, but the hardness of these samples initially increased up 2 hours and then kept constant. TEM images of cold-worked samples showed that new $\mathrm{HCP}$ phase forms after annealing at $950{ }^{\circ} \mathrm{C}$ [23]. On the other hand, some researchers have reported [24,25] that in $\mathrm{Co}-\mathrm{Cr}-\mathrm{Mo}$ superalloys stress can induce martensite transformation after heat treatment of cold-worked alloy and HCP phase can form in their FCC matrix.

This also has been reported that [26], formation of $\varepsilon$-HCP does not occur in nickel stabilized $\gamma$ phase after heat treatment, but the material can undergo the martensite transformation during room-temperature plastic deformation. According to the results that obtained for hardness in this study, it is highly likely to form HCP phase in FCC matrix of L-605 alloy after cold rolling and heat treatment. So, based on the microstructure analysis and hardness results it can be said that in 5,10,20,30 and $35 \%$ cold-worked and annealed samples at $1230{ }^{\circ} \mathrm{C}$ for $10-120 \mathrm{~min}$ and in 5 and $10 \%$ coldworked and annealed samples at $1175^{\circ} \mathrm{C}$ in 10-120 min, new HCP phase forms. Of course, confirmation of this interpretation needs to TEM or EBSD analysis that were not attainable in this work.

\section{Conclusions}

1. A refined grain size for $5,10,20,30$ and $35 \%$ cold-rolled samples was obtained in the subsequent annealing process. Annealing temperature had more significant effect on the average grain size than holding time. Moderate annealing resulted in grain growth; whereas, higher temperature more than $1230{ }^{\circ} \mathrm{C}$ for $20 \%$ cold-rolled sample led to abnormal grain growth. This incident can be related to Zener pinning phenomenon or secondary recrystallization.

2. Recrystallization is observed at temperature range $1068-1230{ }^{\circ} \mathrm{C}$ and grains grow as the annealing temperature increases. At the beginning of the recrystallization, hardness decreases in the time range $0-2$ min as a resulted 
of dislocation annihilation, but then grain growth is accompanied by very low decreasing in hardness.

3. With increasing of cold rolling reduction, the average grain size of crystallized microstructure reduces. For instance, the average grain size of $30 \%$ cold-rolled sample decreases by $28 \%$ after annealing at $1230{ }^{\circ} \mathrm{C}$; whereas, the rate of recrystallization increases.

4. The largest reduction of the L-605 alloy is only about $35 \%$ at room temperature.

\section{Acknowledgement}

The authors gratefully thank Mr. Davood Gholami (School of Metallurgy and Materials Engineering, Iran University of Science and Technology (IUST), Tehran, Iran) and Mr. Hasan Badri (Metallic Materials Research Center (MMRC-MA), Tehran, Iran) for providing us technical supports.

\section{References}

[1] G. D. Sandrock, C.W. Andrews: National Aeronautics and Space Administration (NASA), 1971 Feb. 28p. Report NO.: ND-7051.

[2] Y. Wang, J. Zhao, S. Dai, F. Chen, X. Yu, Y. Zhang: J. Mech. Behav. Biomed. Mater, 27 (2013) 33-42.

[3] H.W. Hayden, S.G. Moffat, J. Wulff: The structure and properties of materials III, First ed., John Wiley \& Sons Inc, New York, 1965.

[4] A. Rollett, F. Humphreys, G.S. Rohrer, M. Hatherly: Recrystallization and related annealing phenomena, 2nd Edition, Elsevier Science Ltd, Amsterdam, 2004, 341 365.

[5] J. Favre, Y. Koizumi, A. Chiba, D. Fabregue, E. Maire, In: 3rd International Symposium on High Temperature Metallurgical Processing, Eds: T. Jiang, J.Y. Hwang, Patrick M asset, O.Yucel, R. Padilla, G. Zhou, John Wiley \& Sons Inc, 2012, 257-265p.

[6] D. Hull, D.J. Bacon: Introduction to dislocations, 4th Edition, The UK: BUTTERWORTH-HEINEMANN, University of Liverpool, 2009, 235-275.

[7] G.E, Dieter, D. Bacon: Mechanical metallurgy, McGraw-Hill book company, The United States of America, 1986, 162-170.

[8] J. Teague, E. Cerreta, M. Stout: Metall. Mater. Trans. A, 35 (2004) 2767-2781.

[9] N. Yukawa, K. Sato, In: Proceedings of International Conference on Strength of Metals and Alloys I (ICSMA I). Eds: The Japan Institute of Metals. Omachi, 1968, 680-86p.

[10] R. Sandstrom, R. Lagneborg: Acta. Met, 23 (1975) 387-398.

[11] W. Roberts, B. Ahlblom: Acta. Met, 26 (1978) 801-813.

[12] K. Song, M. Aindow: Mater. Sci. Eng A-Struct, 479 (2008) 365-372.

[13] J. Harase, R. Shimizu: J. Magn. Magn. Mater, 254-255 (2003) 343-345.

[14] K.J. Ko, J.T. Park, J.K. Kim, MN. Hwang: Scr. Mater, 59 (2008) 764-767.

[15] J. Harase, R. Shimizu: J. Magn. Magn. Mater, 215-216 (2000) 89-91.

[16] Y. Hayakawa, J. Szpunar: Acta. Met, 45 (1997) 4713-4720.

[17] M. Hosseinifar, S. Asgari: Mater. Sci. Eng A-Struct, 527 (2010) 7313-7317.

[18] Y. Lin, M.S. Chen, J. Zhong: J. Mater. Process. Technol, 209 (2009) 2477-2482.

[19] R.D. Doherty: Prog. Mater. Sci, 42 (1997) 39-58. 
[20] R.W. Honeycombe: The plastic deformation of metals. 2nd Edition, Edward arnold, London, 1975.

[21] T. Ericsson: Acta. Met, 14 (1966) 853-865.

[22] P. Huang, H. Lopez: Mater. Lett, 39 (1999) 244-248.

[23] S. Asgari, E. El-Danaf, E. Shaji E, S.R. Kalidindi, R.D. Doherty: Acta Met, 46 (1998) 5795-5806.

[24] Y. Koizumi, S. Suzuki, K. Yamanaka, B.S. Lee, K. Sato, Y. Li, S. Kurosu, H. Matsumoto, A. Chiba: Acta Met, 61 (2013) 1648-1661.

[25] K. Yamanaka, M. Mori, Y. Koizumi, A. Chibaet: J. Mech. Behav. Biomed. Mater, 32 (2014) 52-61.

[26] H. Tawancy, V. Ishwar, B. Lewis: Mater. Lett, 5 (1986) 337-341. 